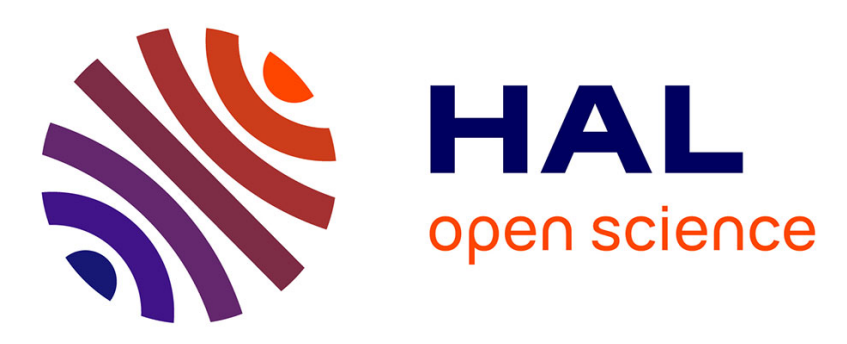

\title{
Insulin-stimulated phosphorylation of endothelial nitric oxide synthase at Ser615 contributes to nitric oxide synthesis
}

\author{
Stuart A Ritchie, Christine F Kohlhaas, Alasdair R Boyd, Krishna C Yalla, \\ Kenneth Walsh, John Mc Connell, Ian P Salt
}

\section{To cite this version:}

Stuart A Ritchie, Christine F Kohlhaas, Alasdair R Boyd, Krishna C Yalla, Kenneth Walsh, et al.. Insulin-stimulated phosphorylation of endothelial nitric oxide synthase at Ser615 contributes to nitric oxide synthesis. Biochemical Journal, 2010, 426 (1), pp.85-90. 10.1042/BJ20091580 . hal-00479271

\section{HAL Id: hal-00479271 \\ https://hal.science/hal-00479271}

Submitted on 30 Apr 2010

HAL is a multi-disciplinary open access archive for the deposit and dissemination of scientific research documents, whether they are published or not. The documents may come from teaching and research institutions in France or abroad, or from public or private research centers.
L'archive ouverte pluridisciplinaire HAL, est destinée au dépôt et à la diffusion de documents scientifiques de niveau recherche, publiés ou non, émanant des établissements d'enseignement et de recherche français ou étrangers, des laboratoires publics ou privés. 


\title{
INSULIN-STIMULATED PHOSPHORYLATION OF ENDOTHELIAL NITRIC OXIDE SYNTHASE AT SER615 CONTRIBUTES TO NITRIC OXIDE SYNTHESIS
}

\author{
Stuart A. Ritchie ${ }^{* \dagger}$, Christine F. Kohlhaas", Alasdair R. Boyd ${ }^{*}$, Krishna C. Yalla*, \\ Kenneth Walsh ${ }^{\ddagger}$, John M. C. ConnelI ${ }^{\dagger}$ and Ian P. Salt ${ }^{*}$
}

*The Henry Wellcome Laboratory for Cell Biology, Division of Molecular and Cellular Biology, Faculty of Biomedical and Life Sciences, Davidson Building, University of Glasgow, Glasgow G12 8QQ, United Kingdom

${ }^{\dagger}$ Division of Cardiovascular and Medical Sciences, Glasgow Cardiovascular Research Centre, University of Glasgow, Glasgow G12 8QQ, United Kingdom

${ }^{\ddagger}$ Molecular Cardiology, Boston University School of Medicine, Boston, MA 02118, United States

$\S$ Corresponding author: e-mail: $\underline{\text { i.salt@ bio.gla.ac.uk }}$

Short title: Insulin-stimulated eNOS phosphorylation at Ser615 and NO synthesis

Abbreviations: Ad.PKB-CA, adenoviruses expressing constitutively active mutant PKB; Ad.PKB-DN, adenoviruses expressing dominant negative mutant PKB; BAECs, bovine aortic endothelial cells; $\mathrm{BH}_{4}$, tetrahydrobiopterin; CaM, calmodulin; eNOS, endothelial nitric oxide synthase; GFP, green fluorescent protein; HAECs, human aortic endothelial cells; HBS, Hepes-buffered saline; HUVECs, human umbilical vein endothelial cells; KRH, Krebs ringer Hepes buffer; L-NMMA, L-N ${ }^{G}$-monomethyl arginine; NO, nitric oxide; PI3K, phosphatidylinositol 3'-kinase; PKB/Akt, protein kinase B; TNF $\alpha$, tumour necrosis factor $\alpha$; VEGF, vascular endothelial growth factor. 


\section{Synopsis}

Insulin stimulates endothelial nitric oxide synthesis via protein kinase B/Akt-mediated phosphorylation and activation of endothelial nitric oxide synthase at Ser1177. In previous studies, we have demonstrated that stimulation of endothelial nitric oxide synthase phosphorylation at Ser1177 may be required, yet is not sufficient for insulin-stimulated nitric oxide synthesis. We therefore investigated the role of phosphorylation of endothelial nitric oxide synthase at alternative sites to Ser1177 as candidate parallel mechanisms contributing to insulin-stimulated nitric oxide synthesis. Stimulation of human aortic endothelial cells with insulin rapidly stimulated phosphorylation of both Ser615 and Ser1177 on endothelial NO synthase, whereas phosphorylation of Ser114, Thr495 and Ser633 was unaffected. Insulin-stimulated Ser615 phosphorylation was abrogated by incubation with the phosphatidylinositol-3'kinase inhibitor, wortmannin, infection with adenoviruses expressing a dominant negative mutant protein kinase B/Akt or preincubation with tumour necrosis factor-alpha but was unaffected by high culture glucose concentrations. Mutation of Ser615 to Ala615 reduced insulin-stimulated nitric oxide synthesis, whereas mutation of Ser615 to Asp615 increased nitric oxide production by nitric oxide synthase in which Ser1177 had been mutated to an Asp1177. We propose that the rapid, protein kinase B-mediated stimulation of phosphorylation of Ser615 contributes to insulin-stimulated nitric oxide synthesis.

KEYWORDS: eNOS, signalling, endothelium 


\section{INTRODUCTION}

Type 2 diabetes is associated with a greatly increased risk of atherosclerosis, yet the molecular mechanisms that underlie this association remain poorly characterised. Endothelial dysfunction, characterised by reduced nitric oxide (NO) bioavailability, is a key early event in the development of atherosclerosis [reviewed in 1]. NO is a key regulator of vascular homeostasis, synthesised by endothelial NO synthase (eNOS). Insulin is a direct-acting vasodilator in intact vessels that has been proposed to contribute to the maintenance of vascular health [2-4], and we and others have demonstrated that insulin stimulates NO synthesis in cultured human endothelial cells [5-6]. Insulin-stimulated NO synthesis is, at least in part, the result of phosphatidylinositol-3'-kinase (PI3K) activation and the subsequent stimulation of protein kinase $\mathrm{B}(\mathrm{PKB} / \mathrm{Akt})$, with resultant phosphorylation and activation of endothelial NO synthase (eNOS) at Ser1177 [6-7]. Furthermore, we have previously demonstrated that culture of human aortic endothelial cells (HAECs) in high glucose abrogated insulin-stimulated NO synthesis, without altering insulin-stimulated phosphorylation of eNOS at Ser1177 or $\mathrm{Ca}^{2+}$-stimulated NO synthesis [6]. These data indicate that stimulation of PKB and subsequent phosphorylation of eNOS Ser1177 may be required, yet not sufficient, for insulin-stimulated NO synthesis under certain conditions. This, in turn, suggests that insulin-stimulated NO synthesis is mediated by more than one signalling mechanism. One candidate mechanism that might underlie insulin-stimulated NO synthesis independent of Ser1177 phosphorylation is the regulation of eNOS by phosphorylation at sites other than Ser1177. We have previously demonstrated that phosphorylation of eNOS at Thr495 is unaffected by insulin [6]. Phosphorylation of eNOS at Ser114, Ser615 and Ser633 have been reported to regulate eNOS activity in response to various stimuli [8-11], yet the effect of acute insulin stimulation on eNOS phosphorylaton at these alternative sites has yet to be determined. In the current study we investigated the role of phosphorylation of eNOS at alternative sites to Ser1177 as potential mechanisms contributing to insulin-stimulated NO synthesis. 


\section{EXPERIMENTAL}

Materials -

Cryopreserved HAECs were purchased from Promocell and large vessel endothelial cell media obtained from TCS Cellworks. Human eNOS cDNA cloned into pcDNA3.1 was a kind gift from Prof. Keith Channon (University of Oxford, Oxford, UK). NADPH, phenformin and tetrahydrobiopterin $\left(\mathrm{BH}_{4}\right)$ were obtained from Sigma. Calmodulin $(\mathrm{CaM})$ was obtained from Merck. Rabbit anti-phospho-eNOS Ser116 (07-357), anti-phospho-eNOS Ser617 (07-561) and anti-phospho-eNOS Ser635 (07-562) (corresponding to Ser114, Ser615 and Ser633 in human eNOS) antibodies were obtained from Upstate Biotech. All other reagents were from sources described previously [6,12-13].

\section{Cell Culture-}

HAECs were grown in large vessel endothelial cell medium and passaged when at $80 \%$ confluence as described previously [6,12-13]. Cells were used for experiments between passages 3 and 6 . HeLa cells were maintained in DMEM supplemented with $10 \%(\mathrm{v} / \mathrm{v})$ foetal calf serum, $100 \mathrm{U} / \mathrm{ml}$ penicillin, $100 \mathrm{mg} / 1$ streptomycin, in a humidified atmosphere of $95 \%(\mathrm{v} / \mathrm{v})$ air: $5 \%(\mathrm{v} / \mathrm{v}) \mathrm{CO}_{2}$ at $37^{\circ} \mathrm{C}$.

\section{Preparation of adenoviruses and infection of HAECs -}

Adenoviruses expressing dominant negative PKB (Ad.PKB-DN), constitutively active PKB (Ad.PKB-CA) or control adenoviruses (Ad.control) were propagated and purified as described previously [14]. HAECs were infected with $5 \mathrm{pfu} /$ cell adenovirus in complete medium and the cells cultured for $48 \mathrm{~h}$ prior to experimentation, with the final $24 \mathrm{~h}$ in serum-free medium. Under these conditions after infection with a green fluorescent protein (GFP)-expressing virus, the majority (>95\%) of HAECs expressed GFP.

Site-directed mutagenesis of eNOS -

Ser615Asp, Ser615Ala, Ser1177Asp and Ser1177Ala mutations were introduced into human eNOS using a QuikChange site-directed mutagenesis kit (Stratagene) using the following primers: Ser615Ala forward 5'-ATAAGATCCGCTTCAACGCCATCTCCTGCTCAGACCC-3'; Ser615Ala reverse 5'-GGGTCTGAGCAGGAGATGGCGTTGAAGCGGATCTTAT-3'; Ser615Asp forward 5'-

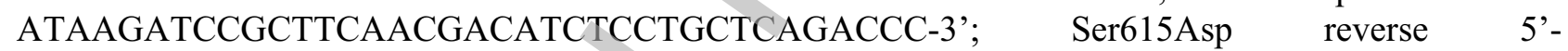
GGGTCTGAGCAGGAGATGTCGTTGAAGCGGATCTTAT-3'; $\quad$ Ser1177Ala forward 5'GCCGCATACGCACCCAGGCCTTTTCCTTGCAGGAGCG-3'; $\quad$ Ser1177Ala reverse 5'CGCTCCTGCAAGGAAAAGGCCTGGGTGCGTATGCGGC-3'; $\quad$ Ser1177Asp forward 5'GCCGCATACGCACCCAGGACTTTTCCTTGCAGGAGCG-3'; $\quad$ Ser1177Asp reverse 5'CGCTCCTGCAAGGAAAAGTCCTGGGTGCGTATGCGGC-3'. Mutant generation was confirmed by sequencing analysis (University of Dundee Sequencing Service, Dundee, UK).

\section{Transfection of HeLa cells}

Mutant DNA $(2 \mu \mathrm{g} /$ well) was mixed with Lipofectamine 2000 (Invitrogen, $4 \mu \mathrm{l} /$ well) in OptiMEM reduced serum medium (Invitrogen, $200 \mu \mathrm{l}$ ) and added to HeLa cells plated on 12-well plates in serum-free culture medium without antibiotics. Cells were incubated for $24 \mathrm{~h}$ in the presence or absence of insulin for the final $5 \mathrm{~min}$, washed with ice-cold PBS and ice-cold lysis buffer (50 mM Tris-HCl pH7.4 at $4^{\circ} \mathrm{C}, 50 \mathrm{mM} \mathrm{NaF}, 1 \%$ (v/v) Triton $\mathrm{X}-100,250 \mathrm{mM}$ mannitol, $5 \mathrm{mM} \mathrm{Na}_{4} \mathrm{P}_{2} \mathrm{O}_{7}, 1 \mathrm{mM} \mathrm{Na} \mathrm{VO}_{4}, 1 \mathrm{mM}$ EDTA, $1 \mathrm{mM}$ EGTA, $1 \mathrm{mM}$ dithiothreitol, $1 \mathrm{mM}$ benzamidine, $0.1 \mathrm{mM}$ phenylmethylsulphonyl fluoride, $5 \mathrm{mg} / \mathrm{l}$ soybean trypsin inhibitor, $80 \mu \mathrm{l}$ ) was added to each well. Cells were scraped into a fresh microcentrifuge tube and centrifuged $\left(11,000 \times \mathrm{g}, 3 \mathrm{~min}, 4^{\circ} \mathrm{C}\right)$. The supernatant was then collected and stored at $-20^{\circ} \mathrm{C}$ prior to analysis.

\section{Preparation of cell lysates, SDS PAGE and Western Blotting -}

Cell lysates were prepared, proteins resolved by SDS-PAGE and subjected to western blotting with the antibodies indicated as described previously [6,12-13].

Evaluation of NO synthesis in cell lysates - 
Cell lysates $(100 \mu \mathrm{g})$ were added to $100 \mu \mathrm{l} 25 \%$ (v/v) 2'-5'-ADP Sepharose in Hepes-buffered saline (HBS) (135 mM NaCl, $5.9 \mathrm{mM} \mathrm{KCl}, 1.2 \mathrm{mM} \mathrm{MgCl}$, $11.6 \mathrm{mM}$ Hepes-NaOH pH7.3) and the volume made up to $300 \mu \mathrm{l}$ with HBS. After incubation at $4^{\circ} \mathrm{C}$ for $3 \mathrm{~h}$ on a rotating mixer, beads were washed twice with $1 \mathrm{ml} \mathrm{HBS}$, twice with $1 \mathrm{ml}$ HBS containing $2 \mathrm{mM}$ EGTA and twice with $1 \mathrm{ml} \mathrm{HBS}$. Pellets were resuspended in $250 \mu \mathrm{l}$ assay buffer (HBS containing $30 \mu \mathrm{M} \mathrm{BH}_{4}, 100 \mu \mathrm{M} \mathrm{L}$-arginine, $1 \mathrm{mM}$ $\mathrm{CaCl}_{2}, 3 \mathrm{mM} \mathrm{NADPH}$ ) and divided into $50 \mu \mathrm{l}$ aliquots. To each aliquot $\mathrm{CaM}$ was added to a final concentration of $0,10,20,100$ or $200 \mathrm{nM}$. Reactions were incubated at $37^{\circ} \mathrm{C}$ for $30 \mathrm{~min}$ and $100 \mu \mathrm{lof}$ ice-cold ethanol added prior to centrifugation $\left(11,000 \mathrm{x} g, 3 \mathrm{~min}, 4^{\circ} \mathrm{C}\right)$. Supernatants were assayed for $\mathrm{NO}_{2}{ }^{-}$content using a Sievers $280 \mathrm{~A}$ NO analyser as described previously [6,12-13].

Evaluation of NO synthesis in cells -

HeLa cells cultured in 12-well plates were incubated in serum-free medium overnight. Cells were preincubated for $1 \mathrm{~h}$ at $37^{\circ} \mathrm{C}$ in $0.5 \mathrm{ml} /$ well Krebs Ringer Hepes (KRH) buffer (119 mM NaCl, $4.75 \mathrm{mM}$ $\mathrm{KCl}, 1.2 \mathrm{mM} \mathrm{MgSO}_{4}, 5 \mathrm{mM} \mathrm{NaHCO} 3,1.3 \mathrm{mM} \mathrm{CaCl}_{2}, 20 \mathrm{mM}$ Hepes-NaOH pH7.4, $1.3 \mathrm{mM} \mathrm{KH}_{2} \mathrm{PO}_{4}, 5$ $\mathrm{mM}$ glucose). The medium was removed and replaced with fresh KRH buffer $(0.5 \mathrm{ml} / \mathrm{well})$ in the presence of various concentrations of test substances. After incubation for various durations, aliquots of media were removed and analyzed using a Sievers 280 A NO analyzer as described previously [6,12-13]. The appropriate control experiments were performed in the presence of the eNOS inhibitor, L-N ${ }^{\mathrm{G}}$ monomethyl arginine (L-NMMA, $0.1 \mathrm{mM}$ ). Data is presented as L-NMMA-sensitive NO synthesis.

\section{Statistics -}

Unless stated otherwise, results are expressed as the mean \pm SEM. Statistically significant differences were determined using a two-tailed Student's $t$ test, with $p<0.05$ deemed significant. 


\section{RESULTS}

Insulin stimulated a significant increase in eNOS phosphorylation at Ser1177 and Ser615 in HAECs (approximately 1.7-fold), yet had no effect on eNOS phosphorylation at Ser114, Thr495 or Ser633 (Figure 1). High $(25 \mathrm{mM})$ culture glucose had no effect on basal or insulin-stimulated phosphorylation of eNOS at any site examined, with the exception of Ser114, which demonstrated reduced phosphorylation (approximately 30\%) in the presence of insulin (Figure 1). Insulin-stimulated eNOS Ser615 phosphorylation was inhibited by preincubation with wortmannin or infection of HAECs with Ad.PKB-DN (Figure 2). Infection of HAECs with Ad.PKB-CA caused a significant increase in basal eNOS Ser615 phosphorylation (Figure 2). Vascular endothelial growth factor (VEGF), which also stimulates PKB, stimulated eNOS Ser615 phosphorylation and insulin-stimulated Ser615 phosphorylation was concomitant with Ser1177 phosphorylation (data not shown).

AMP-activated protein kinase (AMPK) has also been demonstrated to phosphorylate and activate eNOS at Ser1177 [12-13,15]. Incubation of HAECs with the AMPK activator phenformin stimulated phosphorylation of the AMPK substrate acetyl CoA carboxylase and phosphorylation of eNOS at Ser1177, without altering phosphorylation of eNOS at Ser615 or PKB at Ser473 (Figure 3). TNFa has previously been reported to inhibit insulin-stimulated NO synthesis and eNOS Ser1179 (Bovine equivalent to Ser1177) phosphorylation in bovine aortic endothelial cells (BAECs) and reduce insulin receptor phosphorylation in HAECs $[9,16]$. TNF $\alpha$ significantly attenuated insulin-stimulated eNOS Ser615 phosphorylation and PKB Ser473 phosphorylation in HAECs (Figure 3).

As these data indicate that insulin-stimulated phosphorylation of eNOS at both Ser1177 and Ser615 are mediated by PI3K/PKB, we reasoned that concurrent phosphorylation at both sites would influence eNOS activity. HeLa cells (with low endogenous expression of eNOS) were transfected with eNOS mutants in which Ser615 and/or Ser1177 had been mutated to Ala (phospho-null) or Asp (phosphomimetic). Transfection efficiency was approximately equal in each case and mutation of Ser615 had no effect on insulin-stimulated Ser1177 phosphorylation. Similarly, mutation of Ser1177 had no effect on insulin-stimulated Ser615 phosphorylation (Figure 4A). In unstimulated HeLa cells, Ser615 and Ser1 177 phosphorylation was barely detectable (data not shown). ADP Sepharose-purified extracts from untransfected HeLa cells exhibited low levels of NO synthesis that were not sensitive to CaM addition, whereas cells transfected with wild type human eNOS exhibited $\mathrm{Ca}^{2+}$-sensitive NO synthesis (Table 1). $\mathrm{Ca}^{2+}$-sensitive NO synthesis was not significantly different in Ala615 or Asp615 mutants (Table 1). In contrast, eNOS activity was significantly reduced at $200 \mathrm{nM} \mathrm{CaM}$ in the Ala1177 mutant and significantly increased at 10-200 nM CaM in the Asp1177 mutant (Table 1). Mutation of Ser615 to Ala or Asp had no significant effect on eNOS activity or $\mathrm{Ca}^{2+}$ sensitivity in the Ala1177 mutant, yet mutation of Ser615 to Ala significantly reduced Asp1177 mutant eNOS activity at 20-100 nM CaM and eNOS activity was significantly increased at 100-200 nM CaM in the double Asp615-Asp1177 mutant compared to the Asp1177 single mutant (Table 1).

Intact HeLa cells transfected with wild type, Ala615 or Asp615 mutant eNOS exhibited insulinstimulated NO synthesis, whereas NO synthesis was barely detectable in untransfected cells. Basal NO synthesis was significantly increased compared to wild type in cells transfected with Asp1177, Ala615Asp1177 and Asp615-Asp1177 mutant eNOS (Figure 4B). In addition, insulin-stimulated NO synthesis was significantly reduced in cells transfected with the Ala615 mutant compared to wild type (Figure 4B). 


\section{DISCUSSION}

The principal finding of this study was that insulin rapidly stimulates phosphorylation of eNOS at Ser615. Phosphorylation at Ser615 was concomitant with insulin-stimulated phosphorylation of eNOS at Ser1177 and attenuated by the PI3K inhibitor, wortmannin, or infection with adenoviruses expressing dominant-negative mutant PKB. Furthermore, downregulation of Ser615 phosphorylation attenuates insulin-stimulated NO synthesis.

Phosphorylation of eNOS at Ser617 (bovine sequence) has previously been demonstrated in response to bradykinin, VEGF, ATP, endostatin and statins in BAECs [9-11,17]. The current study represents the first evidence of Ser615 phosphorylation in human endothelial cells and identifies insulin as a novel stimulus for Ser615 phosphorylation. Inhibition of PI3K has previously been reported to attenuate bradykinin- and lovastatin-stimulated Ser617 phosphorylation [10-11]. Furthermore, the sequence surrounding Ser615 forms a consensus PKB phosphorylation site and recombinant PKB isolated from wortmannin-treated cells has a reduced capacity to phosphorylate eNOS Ser617 in vitro [10]. In the current study, several lines of evidence support a role for PKB as the eNOS Ser615 kinase; i) infection with Ad.PKB-DN reduced insulin-stimulated Ser615 phosphorylation; ii) insulin-stimulated Ser615 and Ser1177 phosphorylation were concomitant and VEGF, which activates PKB in HAECs stimulated Ser615 phosphorylation [13]; iii) infection with Ad.PKB-CA stimulated eNOS Ser615 phosphorylation; iv) insulin-stimulated phosphorylation of both eNOS at Ser615 and PKB at Ser473 is attenuated in HAECs preincubated with TNF $\alpha$. Activation of AMPK with phenformin had no effect on Ser615 phosphorylation, indicating that unlike Ser1177, Ser615 is not a substrate for AMPK, yet we cannot rule out the possibility that a protein kinase downstream of PKB is responsible for insulin-stimulated Ser615 phosphorylation

Insulin-stimulated Ser1177 phosphorylation was unaffected by high glucose conditions, as described previously [6]. Furthermore, there was no significant change in either basal or insulinstimulated Ser615 phosphorylation in response to high glucose, suggesting that Ser615 phosphorylation is not impaired under high glucose culture conditions. Indeed, as PKB is likely to be responsible for both Ser1177 and Ser615 phosphorylation, it is expected that phosphorylation at both sites is unaffected.

NO synthesis by ADP-Sepharose-purified eNOS from unstimulated HeLa cell lysates was unaffected when eNOS was mutated to Ala615 or Asp615. However, in eNOS Asp1177 mutants, the introduction of an additional Ala615 mutation significantly reduced NO synthesis at 20-100 nM CaM, whereas the introduction of an additional Asp615 mutation increased maximal NO synthesis. In previous studies, the Asp617 mutation (bovine sequence) has been reported to increase the $\mathrm{Ca}^{2+}$-sensitivity of eNOS [10] or increase the $\mathrm{V}_{\max }$ of eNOS [9] in cell-free extracts. Very recently, it was reported that an Asp617/Asp1179 double mutant co-operatively increased $\mathrm{Ca}^{2+}$-sensitivity of eNOS compared to either mutation alone [18], in agreement with the current study. In intact HeLa cells transfected with eNOS mutants, insulin-stimulated NO synthesis by the Ala615 mutant was impaired compared to the wild type enzyme, whereas the Asp615 mutant alone had no significant effect on basal or insulin-stimulated NO synthesis. Previous studies have reported a reduction in eNOS $V_{\max }$ (as assessed by citrulline production), yet modestly increased NO synthesis under ATP-stimulated conditions in COS cells expressing an eNOS Ala617 mutant [9]. Infection of BAECs with adenoviruses expressing Asp617 mutant eNOS has been reported to significantly increase NO synthesis [19]. In addition, mutants in which Ser617, Ser635 and Ser1177 were all mutated to Ala, demonstrated reduced basal and ionomycinstimulated NO synthesis when compared with wild type enzyme [20]. In the current study, we have assayed eNOS-associated and cellular NO synthesis by a subtly different method. It is possible that the different assay methods, eNOS constructs used and stimuli may underlie the lack of effect of Asp615 on the $\mathrm{Ca}^{2+}$-sensitivity or maximum rate of NO synthesis observed in this study.

In agreement with our previous study, Thr495 phosphorylation was unaffected by high glucose or insulin [6]. Similar studies in HUVECs have demonstrated a rapid dephosphorylation of Thr495 in response to insulin that was maximal within $2 \mathrm{~min}$ [21-22]. The reasons for these conflicting data are uncertain, although the different vessels from which the cells were isolated or time course of insulin stimulation may underlie this. Phosphorylation at Ser114 (bovine sequence Ser116) has been demonstrated to be reduced in response to endostatin and VEGF in BAECs [17,23]. Insulin stimulated a 
modest reduction in Ser114 phosphorylation under high glucose conditions. Both dephosporylation $[17,23]$ and phosphorylation [24] of Ser114 has been reported under conditions that activate eNOS, although infection with adenoviruses expressing Asp1 16 mutant eNOS increased the association of eNOS with caveolin-1 and impaired NO synthesis in BAECs and impaired relaxation in aortic rings from eNOS knockout mice, indicating that Ser114 phosphorylation is inhibitory [19].

In conclusion, we propose that upon insulin-mediated PKB stimulation, phosphorylation of both Ser615 and Ser1177 will increase NO synthesis when compared to agents that stimulate Ser1177 alone, whereas phosphorylation of Ser615 alone is not sufficient to stimulate eNOS activity. Further work is necessary to identify the insulin signalling mechanisms impaired by high glucose culture conditions. Such studies should include an analysis of the regulation of subcellular localisation of eNOS and/or association of eNOS with caveolin-1 and/or Hsp90 [25-26].

\section{ACKNOWLEDGEMENTS}

This work was supported by a Medical Research Council Clinical Research Training Fellowship to S.A.R.; a Wellcome Trust PhD Studentship to C.F.K.; and a Diabetes UK R.D. Lawrence Fellowship to I.P.S. 


\section{References}

1. Potenza, M. A., Gagliardi, S., Nacci, C., Carratu', M. R. and Montagnani, M. (2009) Endothelial dysfunction in diabetes: from mechanisms to therapeutic targets. Curr. Med. Chem. 16, 94-112.

2. Potenza M. A., Addabbo, F. and Montagnani, M. (2009) Vascular actions of insulin with implications for endothelial dysfunction. Am. J. Physiol. Endocrinol. Metab. 297, E568-E577.

3. Steinberg, H. O., Brechtel, G., Johnson, A., Fineberg, N. and Baron, A. D. (1994) Insulinmediated skeletal muscle vasodilation is nitric oxide dependent. A novel action of insulin to increase nitric oxide release. J. Clin. Invest. 94, 1172-1174

4. Ueda, S., Petrie, J. R., Cleland, S. J., Elliott, H. L. and Connell, J. M. (1998) The vasodilating effect of insulin is dependent on local glucose uptake: a double blind, placebo-controlled study. $\mathrm{J}$. Clin. Endocrinol. Metab. 83, 2126-2131

5. Zeng, G. and Quon, M. J. (1996) Insulin-stimulated production of nitric oxide is inhibited by wortmannin. Direct measurement in vascular endothelial cells. J. Clin. Invest. 98, 894-898

6. Salt, I. P., Morrow, V. A., Brandie, F. M., Connell, J. M. C. and Petrie, J. R. (2003) High glucose inhibits insulin-stimulated nitric oxide production without reducing eNOS Ser1177 phosphorylation in human aortic endothelial cells. J. Biol. Chem. 278, 18791-18797

7. Kim, F., Gallis, B. and Corson, M. A. (2001) TNF-alpha inhibits flow and insulin signaling leading to NO production in aortic endothelial cells. Am. J. Physiol. Cell. Physiol. 280, C1057C1065

8. Mount, P. F., Kemp, B. E. and Power, D. A. (2007) Regulation of endothelial and myocardial NO synthesis by multi-site eNOS phosphorylation. J. Mol. Cell. Cardiol. 42, 271-279

9. Bauer, P. M., Fulton, D., Boo, Y. C., Sorescu, G. P., Kemp, B. E., Jo, H. and Sessa, W. C. (2003) Compensatory phosphorylation and protein-protein interactions revealed by loss of function and gain of function mutants of multiple serine phosphorylation sites in endothelial nitric-oxide synthase. J. Biol. Chem. 278, 14841-14849

10. Michell, B, J., Harris, M. B., Chen, Z. P., Ju, H., Venema, V. J., Blackstone, M. A., Huang, W., Venema, R, C. and Kemp, B. E. (2002) Identification of regulatory sites of phosphorylation of the bovine endothelial nitric-oxide synthase at serine 617 and serine 635. J. Biol. Chem. 277, 4234442351

11. Harris, M. B., Blackstone, M. A., Sood, S. G., Li, C., Goolsby, J. M., Venema, V. J., Kemp, B. E. and Venema, R. C. (2004) Acute activation and phosphorylation of endothelial nitric oxide synthase by HMG-CoA reductase inhibitors. Am. J. Physiol. Heart. Circ. Physiol. 287, H560H566

12. Boyle, J. G., Logan, P. J., Ewart, M. A., Reihill, J. A., Ritchie, S. A., Connell, J. M. C., Cleland, S. J. And Salt, I. P. (2008) Rosiglitazone stimulates nitric oxide synthesis in human aortic endothelial cells via AMP-activated protein kinase. J. Biol. Chem. 283, 11210-11217

13. Reihill, J. A., Ewart, M. A., Hardie, D. G. and Salt, I. P. (2007) AMP-activated protein kinase mediates VEGF-stimulated endothelial NO production. Biochem. Biophys. Res. Commun. 354, 1084-1088

14. Luo, Z., Fujio, Y., Kureishi, Y., Rudic, R. D., Daumerie, G., Fulton, D., Sessa, W. C. and Walsh, K. (2000) Acute modulation of endothelial Akt/PKB activity alters nitric oxide-dependent vasomotor activity in vivo. J. Clin. Invest. 106, 493-499

15. Morrow, V. A., Foufelle, F., Connell, J. M. C., Petrie, J. R., Gould, G. W. and Salt, I. P. (2003) Direct activation of AMP-activated protein kinase stimulates nitric-oxide synthesis in human aortic endothelial cells. J. Biol. Chem. 278, 31629-31639

16. Aljada, A., Ghanim, H., Assian, E. and Dandona, P. (2002) Tumor necrosis factor-alpha inhibits insulin-induced increase in endothelial nitric oxide synthase and reduces insulin receptor content and phosphorylation in human aortic endothelial cells. Metabolism 51, 487-491.

17. Li, C., Harris, M. B., Venema, V. J. and Venema, R. C. (2005) Endostatin induces acute endothelial nitric oxide and prostacyclin release. Biochem. Biophys. Res. Commun. 329,873-878 
18. Tran, Q. K., Leonard, J., Black, D. J., Nadeau, O. W., Boulatnikov, I. G. and Persechini, A. (2009) Effects of combined phosphorylation at Ser-617 and Ser-1179 in endothelial nitric oxide synthase on $\mathrm{EC}_{50}\left(\mathrm{Ca}^{2+}\right)$ values for calmodulin binding and enzyme activation. J. Biol. Chem. 284, 1189211899

19. Li, C., Ruan, L., Sood, S. G., Papapetropoulos, A., Fulton, D. and Venema, R. C. (2007) Role of eNOS phosphorylation at Ser-116 in regulation of eNOS activity in endothelial cells. Vasc. Pharmacol. 47, 257-264

20. Church, J. E. and Fulton, D. (2006) Differences in eNOS activity because of subcellular localisation are dictated by phosphorylation state rather than the local calcium environment. J. Biol. Chem. 281, 1477-1488

21. Federici, M., Pandolfi, A., De Filippis, E. A., Pellegrini, G., Menghini, R., Lauro, D., Cardellini, M., Romano, M., Sesti, G., Lauro, R. and Consoli, A. (2004) G972R IRS-1 variant impairs insulin regulation of endothelial nitric oxide synthase in cultured human endothelial cells. Circulation 109, 399-405

22. Andreozzi, F., Laratta, E., Procopio, C., Hribal, M. L., Sciacqua, A., Perticone, M., Miele, C., Perticone, F and Sesti, G. (2007) Interleukin-6 impairs the insulin signalling pathway, promoting production of nitric oxide in human umbilical vein endothelial cells. Mol. Cell. Biol. 27, 23722783

23. Kou, R., Greif, D. and Michel, T. (2002) Dephosphorylation of endothelial nitric-oxide synthase by vascular endothelial growth factor. Implications for the vascular responses to cyclosporin A. J. Biol. Chem. 277, 29669-29673

24. Gallis, B., Corthals, G. L., Goodlett, D. R., Ueba, H., Kim, F., Presnell, S. R., Figeys, D., Harrison, D. G., Berk, B. C., Aebersold, R. and Corson, M. A. (1999) Identification of flowdependent endothelial nitric-oxide synthase phosphorylation sites by mass spectrometry and regulation of phosphorylation and nitric oxide production by the phosphatidylinositol 3-kinase inhibitor LY294002. J. Biol. Chem. 274, 30101-30108

25. Takahashi, S. and Mendelsohn, M. E. (2003) Synergistic activation of endothelial nitric-oxide synthase (eNOS) by HSP90 and Akt: calcium-independent eNOS activation involves formation of an HSP90-Akt-CaM-bound eNOS complex. J. Biol. Chem. 278, 30821-30827

26. Repetto, S., Salani, B., Maggi, D. and Cordera, R. (2005) Insulin and IGF-I phosphorylate eNOS in HUVECs by a caveolin-1 dependent mechanism. Biochem. Biophys. Res. Commun. 337, 849852 


\section{Table 1 The effect of Ser615/Ser1177 phosphorylation on NO synthesis}

HeLa cells were transfected with eNOS mutants and lysates prepared. Lysates were assessed for NO synthesis in the presence of 0-200 $\mathrm{nM} \mathrm{CaM}$. Values stated are the mean $\pm \mathrm{SD} n \mathrm{nmol} \mathrm{NO}_{2}{ }^{-} / \mathrm{hr} / \mathrm{mg}$ lysate and results from three independent experiments are shown. ${ }^{*} \mathrm{p}<0.05$ relative to value in wild type (WT), $*^{*} \mathrm{p}<0.05$ relative to value in Asp1177 mutant.

\begin{tabular}{lcccccc}
\hline Calmodulin (nM) & \multicolumn{1}{c}{$\mathbf{0}$} & \multicolumn{1}{c}{$\mathbf{1 0}$} & \multicolumn{1}{c}{$\mathbf{2 0}$} & \multicolumn{1}{c}{$\mathbf{1 0 0}$} & \multicolumn{2}{c}{$\mathbf{2 0 0}$} \\
\hline Untransfected & $\mathbf{0 . 2 0} \pm \mathbf{0 . 0 6}$ & $\mathbf{0 . 2 0} \pm \mathbf{0 . 0 5}$ & $\mathbf{0 . 1 9} \pm \mathbf{0 . 0 6}$ & $\mathbf{0 . 2 4} \pm \mathbf{0 . 0 4}$ & $\mathbf{0 . 2 2} \pm \mathbf{0 . 0 5}$ \\
Wild type & $\mathbf{0 . 6 0} \pm \mathbf{0 . 1 4}$ & $\mathbf{0 . 7 4} \pm \mathbf{0 . 0 6}$ & $\mathbf{1 . 6 4} \pm \mathbf{0 . 2 9}$ & $\mathbf{2 . 5 4} \pm \mathbf{0 . 1 3}$ & $\mathbf{3 . 3 8} \pm \mathbf{0 . 4 0}$ \\
Ala615 & $\mathbf{0 . 5 3} \pm \mathbf{0 . 1 7}$ & $\mathbf{0 . 6 7} \pm \mathbf{0 . 1 8}$ & $\mathbf{1 . 4 5} \pm \mathbf{0 . 1 5}$ & $\mathbf{2 . 3 7} \pm \mathbf{0 . 0 4}$ & $\mathbf{2 . 7 3} \pm \mathbf{0 . 3 3}$ \\
Asp615 & $\mathbf{0 . 7 2} \pm \mathbf{0 . 1 7}$ & $\mathbf{0 . 9 5} \pm \mathbf{0 . 2 7}$ & $\mathbf{1 . 7 2} \pm \mathbf{0 . 5 6}$ & $\mathbf{2 . 7 6} \pm \mathbf{0 . 1 7}$ & $\mathbf{3 . 6 3} \pm \mathbf{0 . 1 6}$ \\
Ala1177 & $\mathbf{0 . 5 7} \pm \mathbf{0 . 2 4}$ & $\mathbf{0 . 7 6} \pm \mathbf{0 . 2 0}$ & $\mathbf{1 . 3 6} \pm \mathbf{0 . 2 7}$ & $\mathbf{2 . 0 8} \pm \mathbf{0 . 5 0}$ & $\mathbf{2 . 4 1} \pm \mathbf{0 . 3 4}$ \\
Asp1177 & $\mathbf{0 . 8 4} \pm \mathbf{0 . 0 5}$ & $\mathbf{2 . 8 0} \pm \mathbf{0 . 6 3} *$ & $\mathbf{5 . 8 1} \pm \mathbf{0 . 3 3} *$ & $\mathbf{5 . 5 0} \pm \mathbf{0 . 5 8} *$ & $\mathbf{6 . 2 9} \pm \mathbf{1 . 6 5 *}$ \\
Ala615 Ala1177 & $\mathbf{0 . 3 5} \pm \mathbf{0 . 2 6}$ & $\mathbf{0 . 5 7} \pm \mathbf{0 . 1 4}$ & $\mathbf{1 . 1 8} \pm \mathbf{0 . 2 3}$ & $\mathbf{1 . 5 3} \pm \mathbf{0 . 2 9}$ & $\mathbf{2 . 4 1} \pm \mathbf{0 . 4 0}$ \\
Ala615 Asp1177 & $\mathbf{0 . 6 5} \pm \mathbf{0 . 1 6}$ & $\mathbf{1 . 9 9} \pm \mathbf{0 . 6 0}$ & $\mathbf{4 . 0 2} \pm \mathbf{0 . 3 3} * *$ & $\mathbf{4 . 6 3} \pm \mathbf{0 . 3 2} * *$ & $\mathbf{5 . 2 1} \pm \mathbf{1 . 5 0}$ \\
Asp615 Ala1177 & $\mathbf{0 . 6 3} \pm \mathbf{0 . 2 8}$ & $\mathbf{1 . 0 1} \pm \mathbf{0 . 4 3}$ & $\mathbf{1 . 4 2} \pm \mathbf{0 . 2 4}$ & $\mathbf{2 . 2 4} \pm \mathbf{0 . 5 5}$ & $\mathbf{2 . 5 6} \pm \mathbf{0 . 3 5}$ \\
Asp615 Asp1177 & $\mathbf{0 . 8 9} \pm \mathbf{0 . 2 8}$ & $\mathbf{3 . 5 2} \pm \mathbf{0 . 9 1}$ & $\mathbf{5 . 7 9} \pm \mathbf{0 . 7 3}$ & $\mathbf{8 . 4 7} \pm \mathbf{1 . 1 5} * *$ & $\mathbf{9 . 7 7} \pm \mathbf{0 . 7 3} * *$ \\
\hline
\end{tabular}




\section{FIGURE LEGENDS}

Figure 1 The effect of insulin on eNOS phosphorylation in HAECs

HAECs were incubated in $5 \mathrm{mM}$ glucose, $5 \mathrm{mM}$ glucose $+20 \mathrm{mM}$ mannitol (man) or $25 \mathrm{mM}$ glucose (glc) for $48 \mathrm{~h}$ and subsequently incubated in the presence or absence of insulin (ins, $1 \mu \mathrm{M}, 10 \mathrm{~min}$ ). Lysates were prepared and subjected to immunoblotting with antibodies raised against phosphorylated eNOS at the sites indicated. A) Representative immunoblots are shown. B) Quantification of immunoblots from six (Thr495, Ser633, Ser1177) or eight (Ser114, Ser615) independent experiments ${ }^{*} \mathrm{p}<0.05$ relative to value in absence of insulin. ${ }^{* *} \mathrm{p}<0.05$ relative to value in absence of high glucose.

\section{Figure 2 Insulin-stimulated eNOS Ser615 phosphorylation is PI3K/PKB-dependent}

Lysates were subjected to immunoblotting with the indicated antibodies after preparation from HAECs A, B) incubated in the presence or absence of insulin $(1 \mu \mathrm{M}, 10 \mathrm{~min})$ and wortmannin (100 $\mathrm{nM}, 45 \mathrm{~min}$ ) or $\mathrm{C}, \mathrm{D}$ ) infected with the indicated adenoviruses for $48 \mathrm{~h}$, prior to incubation in the presence or absence of insulin (1 $\mu \mathrm{M}, 15 \mathrm{~min})$. A, C) Representative immunoblots are shown. B, D) Quantification of immunoblots from three independent experiments. ${ }^{*}<0.05$ relative to vehicle, $* * \mathrm{p}<0.05$ relative to absence of wortmannin, ${ }^{* * *} \mathrm{p}<0.05$ relative to value in presence of Ad.control.

\section{Figure 3 Effect of TNF $\alpha$ and phenformin on Ser615 phosphorylation}

HAEC lysates were subjected to immunoblotting with the indicated antibodies after preparation from HAECs preincubated in the presence or absence of A) $2 \mathrm{mM}$ phenformin for $30 \mathrm{~min}$ or $\mathrm{B}, \mathrm{C}$ ) TNF $\alpha$ $(10 \mathrm{ng} / \mathrm{ml}, 6 \mathrm{~h})$ and insulin $(1 \mu \mathrm{M}, 10 \mathrm{~min})$. A, B) Representative immunoblots are shown, repeated on three occasions. C) Quantification of immunoblots for eNOS S615 (white bars) or PKB S473 phosphorylation. ${ }^{*} \mathrm{p}<0.01$ relative to vehicle, ${ }^{*} \mathrm{p}<0.05$ relative to absence of $\mathrm{TNF} \alpha, \$ \mathrm{p}<0.01$ relative to absence of TNF $\alpha$.

\section{Figure 4 Transfection of HeLa cells with eNOS Ser615 and Ser1177 mutants}

HeLa cells were transfected with the eNOS mutants indicated, stimulated with insulin $(1 \mu \mathrm{M}, 10 \mathrm{~min})$ and A) lysates prepared or B) NO synthesis assessed. A) Lysates were subjected to immunoblotting with the antibodies indicated. Representative immunoblots are shown from three independent experiments. B) Results are shown from three independent experiments. ${ }^{*} p<0.05$ relative to absence of insulin, $* * \mathrm{p}<0.05$ relative to wild type value. 
A

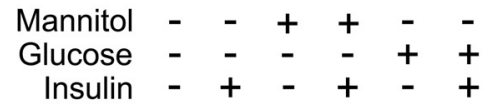

P-eNOS S114

P-eNOS S615

eNOS

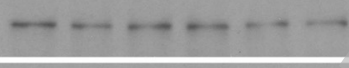

Mannitol
Glucose

Insulin - - +++

P-eNOS S633

P-eNOS T495

P-eNOS S1177

eNOS
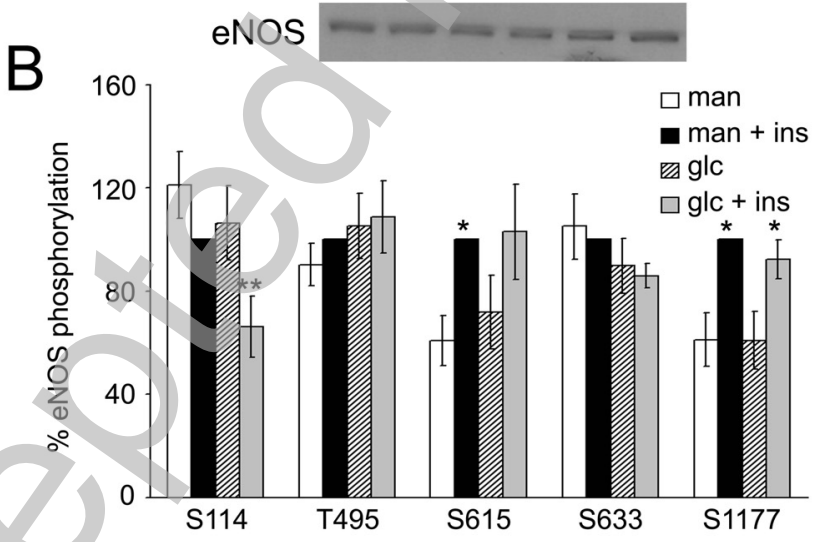


\section{A}

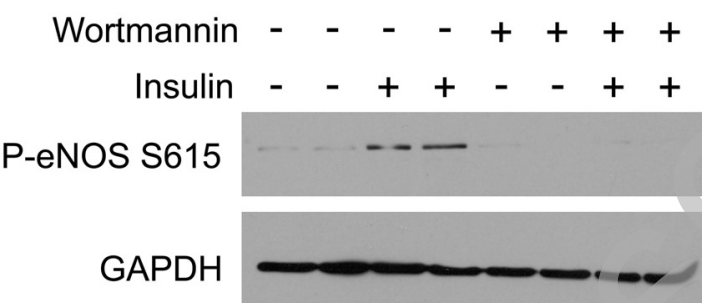

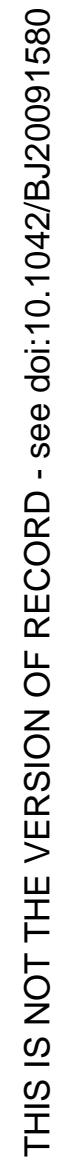

B

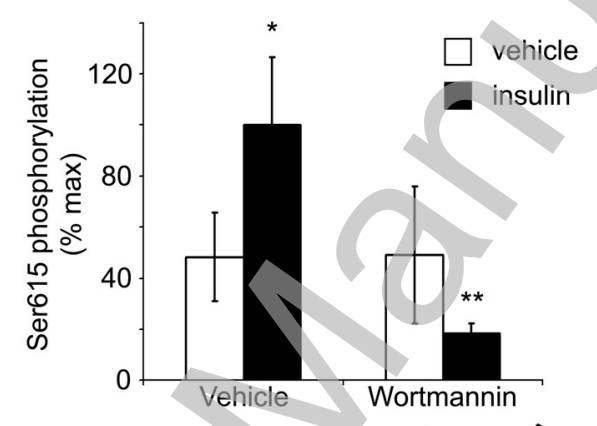

C

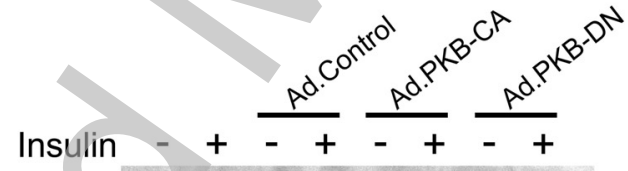

P-eNOS S615

eNOS $-m-m-m-$

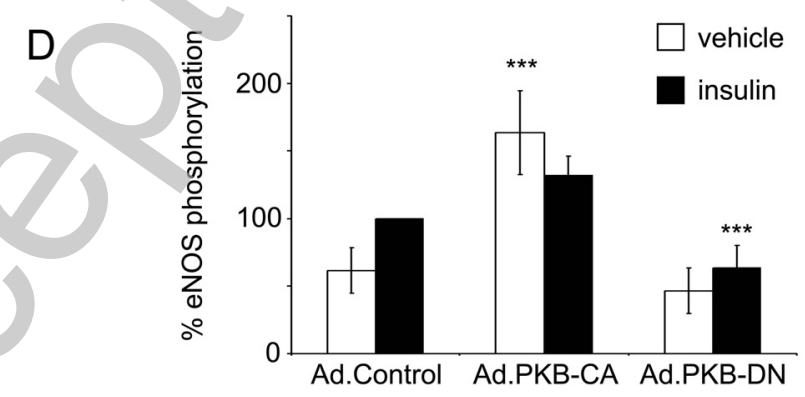


A

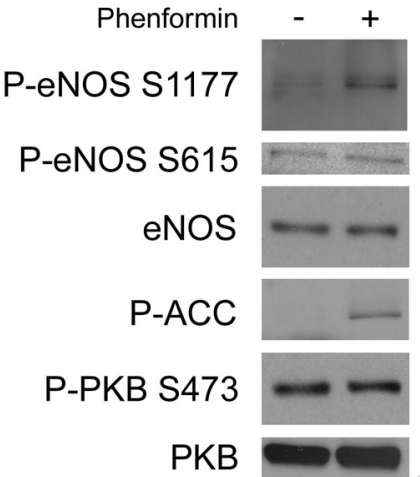

B

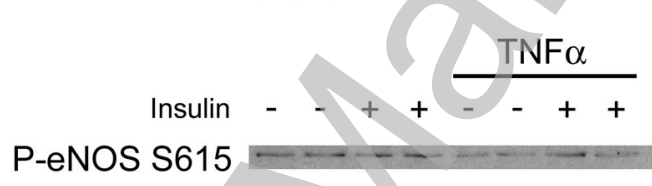

eNOS

P-PKB S473

PKB

C 120$] *$ aP-eNOS S615

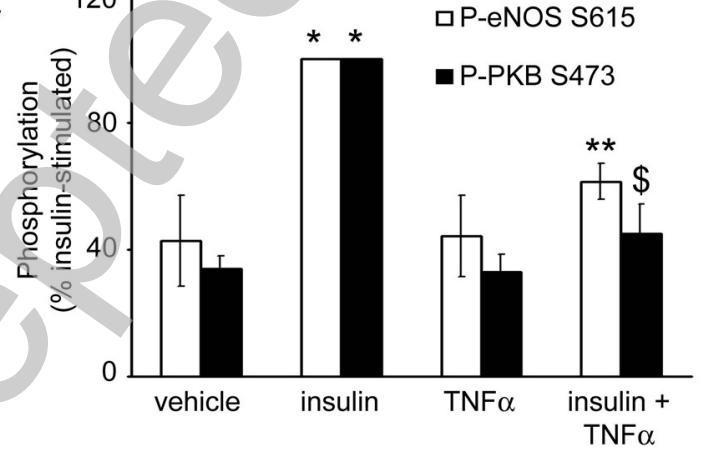


A

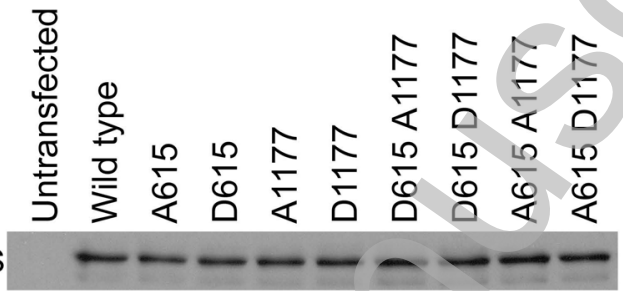

P-eNOS S615

P-eNOS S1177

AMPKo1

B a vehicle

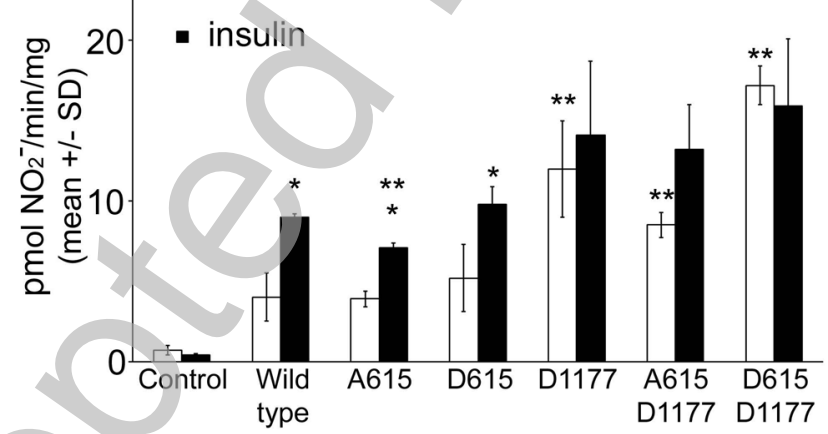

